\title{
The Effect of Aqueous Phase Recirculation During Hydrothermal Liquefaction of Spent Coffee Grounds
}

\author{
J.J Grobler and C.J Schabort
}

\begin{abstract}
Batch hydrothermal liquefaction of spent coffee grounds was done in this study. The effect of subsequent diluted aqueous phase recirculation was studied at a constant temperature of $275^{\circ} \mathrm{C}$ and residence time of 10 minutes. Four recirculation reactions were completed following a control reaction and the results were compared. It was found that the recirculation of the aqueous phase had increased the bio-oil mass yield by $51 \%$. An increase in the organics and nitrogen concentration was observed in the aqueous phase, while the total organic carbon decreased due to migration of carbon species to the bio-oil product phase. The bio-oil retained its high energy content following the recirculation reactions with a higher heating value of $32.61 \mathrm{MJ} / \mathrm{kg}$. The main component of the bio-oil was identified as $\mathrm{C}_{16^{-}}$ $\mathrm{C}_{18}$ aliphatic acids with long carbon chain hydrocarbons.
\end{abstract}

Index Terms - aqueous phase recirculation, batch hydrothermal liquefaction, spent coffee grounds.

\section{INTRODUCTION}

There is an increasing demand for cost-effective and sustainable renewable energy sources that result in lower greenhouse gas emissions [1]. Biofuels that are produced from biomass, are among the most environmentally friendly alternative energy sources [2]. Hydrothermal liquefaction (HTL) is regarded as one of the leading prospects for the production of biofuels from biomass [3]. HTL is a thermochemical process that can handle wet feedstock due to water being used both as a catalyst and reagent. The HTL reaction occurs at an elevated temperature at which water is in a subcritical state as well as elevated pressure to keep the water in a liquid state [4]. The main products that are produced by the HTL process are bio-oil, bio-char, an aqueous phase (AP), and a bio-gas product [5].

Using waste and residue biomass as feedstock increases the amount of biomass that is available and negates competition with food resources [6]. Spent coffee grounds (SCG), which is a residue from the processing of coffee beans to produce coffee, has been identified as a promising HTL feedstock [7]. Coffee is

Manuscript received October 20, 2018. This work was supported by the North West University (NWU) Potchefstroom Campus, Faculty of Engineering.

J.J Grobler is a final year chemical engineering student at NWU (e-mail: jj.25044575@gmail.com) one of the most consumed beverages on a global scale [8]. This leads to large amounts of SCG that are underutilized and sent to landfills for disposal. There is thus an abundance of SCG as a feedstock for HTL [7].

To the knowledge of the author at the time this article was written, the only other study done on HTL of SCG was done by Yang et al. [7], who reported the largest yield of bio-oil product at a temperature of $275{ }^{\circ} \mathrm{C}$, a residence time of 10 minutes and an initial pressure of $1 \mathrm{MPa}$.

The recirculation of the AP is the subsequent use of diluted or non-diluted AP as solvent for consecutive reactions [3]. Concentration of organics in the AP due to recirculation can lead to saturation effects that cause compounds to migrate to other product phases, such as the bio-oil product phase [9]. This leads to the tendency of the bio-oil yield to increase with subsequent recirculation reactions $[5,10]$. Another tendency noted, relates to an increase in nitrogen found in the AP while there is a decrease in the carbon content of the AP $[5,10]$. The recirculation of the AP shows a lesser impact on the bio-char with only slight changes in the mass yield [10]. The AP resulting volume and therefore mass yield also tends to decrease with subsequent AP recirculation [11].

\section{EXPERIMENTAL METHODS}

\section{A. Materials}

The SCG that was used for the experiments was collected from a local coffee shop in Potchefstroom. The SCG was dried for two days at $80^{\circ} \mathrm{C}$ and stored in sealed glass containers to prevent reabsorption of moisture. Deionized water was used as solvent and dilution liquid for the experiments. Acetone and nhexane, both supplied by ACE Chemicals and used as received, were used as extraction solvents.

\section{B. Apparatus}

A $950 \mathrm{~cm}^{3}$ stainless-steel autoclave batch reactor was used to conduct all of the experiments. The reactor is equipped with a

C.J Schabort is with the School of Chemical and Minerals Engineering, North West University, Potchefstroom campus (e-mail: corneels.schabort@nwu.ac.za) 
removable stainless steel cup that aids in the effective removal of the product after the reactions. The reactor is also equipped with a thermocouple, manual gas vent valve and a pressure release valve. A heating mantle is utilized to supply the heat required for the reactions.

For the extraction and separation of the products a $2 \mathrm{~L}$ flask was used to hold the product and extraction solvent. A heating plate with a water bath was utilized as the heat source during product extraction. The solid-liquid separation was done via Büchner vacuum filtration while insoluble liquids were separated by use of a separation funnel. The reactor setup and solvent extraction setup are shown in Fig. 1 and Fig. 2, respectively.

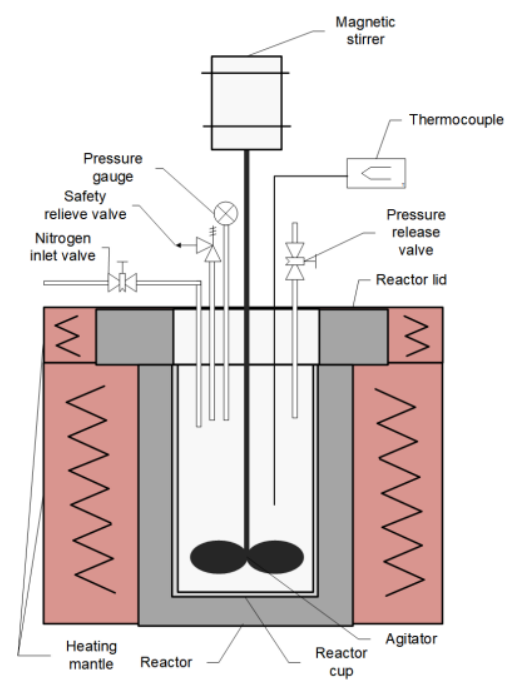

Fig. 1. Hydrothermal liquefaction reactor setup.

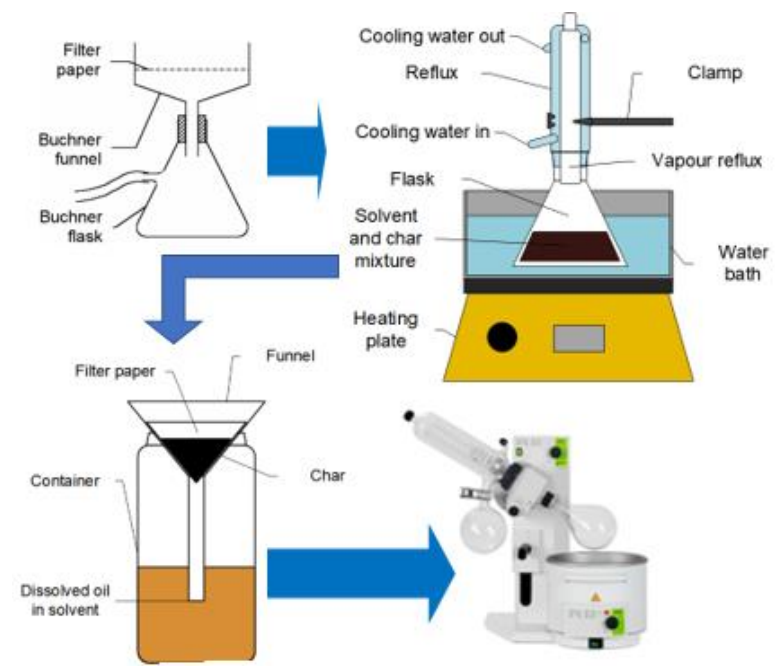

Fig. 2. Product separation setup.

\section{Procedure}

\section{1) Reactor preparation and reactions}

For the control experiment, $300 \mathrm{~g}$ of deionized water was used as solvent. For the subsequent runs $195 \mathrm{~g}$ of AP from the previous reaction was mixed with $105 \mathrm{~g}$ of deionized water to create the diluted recirculation solvent that consists of $65 \mathrm{wt} \%$ AP and 35 wt $\%$ deionized water.

For each reaction the reactor cup was loaded with $90 \mathrm{~g} \mathrm{(30 \%}$ mass fraction based on solvent mass) of the SCG and $300 \mathrm{~g}$ of solvent. The mixture was agitated until a homogenous mixture was obtained. The reactor cup was replaced in the reactor, after which the reactor was closed and the heating mantle connected following a standard operating procedure (SOP) to ensure a safe environment during experiments. Thereafter the reactor was purged with nitrogen for three times to create an inert oxygen free atmosphere. The reactor was charged to an initial pressure of $1 \mathrm{MPa}$. The reactor was then heated to the desired reaction temperature of $275^{\circ} \mathrm{C}$. Upon reaching the desired set point temperature of $275^{\circ} \mathrm{C}$, the temperature was kept stable for a 10minute residence time. Following the reaction, the reactor was left to cool to $30{ }^{\circ} \mathrm{C}$ under forced convection, where after product extraction commenced.

\section{2) Product separation and extraction}

Following the reaction, the product was removed from reactor cup. The cup was rinsed with $200 \mathrm{~mL}$ of n-hexane to remove any remaining organics. The solid-liquid product mixture was filtered using Büchner vacuum filtration, where the filtrate contained the AP product along with bio-oil product dissolved in the washing n-hexane. The insoluble n-hexane and AP mixture was then separated using a separation funnel.

The solid phase that had remained on the filter paper was the bio-char product that still contained trapped bio-oil in the pores of the char. To remove the bio-oil from the pores of the char, the char was placed in a flask along with $750 \mathrm{~mL}$ of n-hexane. The flask was then equipped with a reflux and placed in the heated water bath at $70{ }^{\circ} \mathrm{C}$. The solvent and char mixture was left to boil for two hours. Following the n-hexane extraction the char was gravity filtered to obtain the n-hexane with dissolved bio-oil. The remaining char was then placed in the flask and 750 $\mathrm{mL}$ of acetone added. The same procedure was then followed to obtain dissolved oils in acetone. The char was then dried for 24 hours in a convection oven at $80^{\circ} \mathrm{C}$. Following the drying, the char was weighed to obtain the mass yield.

The extraction solvents were reclaimed using evaporation under reduced pressure. The oils were cooled in an ice bath to solidify and the remaining moisture was decanted into the AP. The remaining bio-oil and the AP was then weighed to obtain the respective mass yields.

\section{Product analysis}

\section{1) Bio-oil}

The composition of the bio-oil was determined using an Agilent Technologies 7890GC with 5975C inert MSD GC-MS, where dichloromethane was used as solvent for the hexane extracted oils and methanol was used as solvent for the acetone extracted oils. The GC-MS results were then confirmed with 
FT-IR analysis on a Shimadzu IRAffinity-1 spectrophotometer. The higher heating value (HHV) was determined by a IKA C5003 calorific value analyzer.

\section{2) Bio-char}

The HHV was determined by a IKA C5003 calorific value analyzer.

\section{3) Aqueous phase}

The chemical oxygen demand (COD), total nitrogen (TN) content and total organic carbon (TOC) was determined using Macherey-Nagel Nanocolor COD 1500, TN 220 and TOC 600 testing kits respectively.

\section{RESULTS AND DISCUSSION}

\section{1) Mass yield of products}

The effect of AP recirculation on the bio-oil, bio-char, and AP product phases were studied by four consecutive recirculation reaction experiments. The mass yields that were obtained for the bio-oil, char, and AP are reported in Fig. 3.

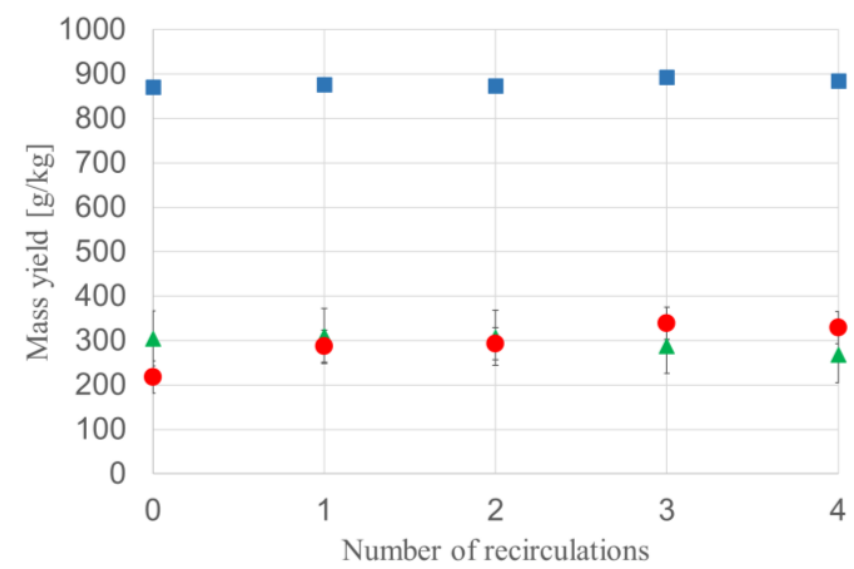

Fig. 3. Mass yields of bio-oil, bio-char, and aqueous phase product for the four recirculation reactions $(\bullet$ total bio-oil, $\Delta$ bio-char, aqueous phase)

It can be noted from Fig. 3 that the bio-oil yield increases with each subsequent recirculation. The initial mass yield for the bio-oil was recorder as $217.8 \mathrm{~g} / \mathrm{kg}$ which then increased for each subsequent recirculation reaction up to the fourth reaction for which yield was recorder as $328.9 \mathrm{~g} / \mathrm{kg}$. An overall increase of $111.1 \mathrm{~g} / \mathrm{kg}$ was thus achieved, which translates into an increase in bio-oil mass yield of $51 \%$ after the $4^{\text {th }}$ recirculation. This increase can be explained by concentration of organic species in the aqueous phase bringing about saturation effects in the AP that can cause the shift of carbon species from the AP to other product phases such as the bio-oil phase. Furthermore, since a number of the carbon species that were present in the previous reactions' AP was reintroduced into the new reaction via recirculation of said AP, these species are afforded another opportunity to reactant and possibly undergo degradation or polymerisation into the bio-oil product phase.

AP recirculation had a lesser impact on the mass yield of the bio-char with the yield remaining relatively constant for the first two recirculation reactions with a mass yield of $310.0 \mathrm{~g} / \mathrm{kg}$ and $306.7 \mathrm{~g} / \mathrm{kg}$ respectively. The mass yield then dropped slightly by $18.9 \mathrm{~g} / \mathrm{kg}$ for the $3^{\text {rd }}$ reaction and by a further $20.0 \mathrm{~g} / \mathrm{kg}$ for the $4^{\text {th }}$ reaction resulting in mass yields of $287.8 \mathrm{~g} / \mathrm{kg}$ and 267.8 $\mathrm{g} / \mathrm{kg}$ respectively. Overall the mass yield of the char had dropped by $36.6 \mathrm{~g} / \mathrm{kg}$ from the control experiment which had a char mass yield of $304.4 \mathrm{~g} / \mathrm{kg}$. This decrease in mass yield for the char is thought to be a result of increased carbon species degradation to the bio-oil phase, brought on by shifts in component distribution due to the effects as explained previously.

The AP recirculation showed virtually no effect on mass yield of the AP as the yield had remained relatively constant throughout, ranging between $874.0 \mathrm{~g} / \mathrm{kg}$ and $893.3 \mathrm{~g} / \mathrm{kg}$ with no discernible trend present. From literature it is expected that the mass would decrease with each consecutive recirculation reaction. However, since the AP that is recycled is diluted before each consecutive reaction and the total solvent weight for each reaction equals $300 \mathrm{~g}$, the decrease in the mass yield of the resulting AP is not apparent. The constituency was still subject to changes despite the consistent mass yield that had been obtained for the AP. This was confirmed through the characterisation of the AP and is reported in Table III.

It is therefore suggested that the additional material constituting the increase in the bio-oil mass yield was derived from the AP. It is further speculated that some of the additional material for the bio-oil can originate from the gas phase also, however this statement requires further validation as the gas phase had not been fully quantified.

\section{2) Characterization of bio-oil}

The major volatile components in the bio-oil product were identified using GC-MS analysis and are reported in Table I.

TABLE I: MAJOR VOLATILE COMPONENTS FOUND IN BIO-OIL BY GC-MS ANALYSIS

\begin{tabular}{|c|c|c|c|c|c|c|}
\hline \multirow[t]{2}{*}{ Compound name } & \multirow[t]{2}{*}{ Formula } & \multicolumn{5}{|c|}{$\begin{array}{l}\text { Area \% for each } \\
\text { recirculation reaction }\end{array}$} \\
\hline & & 0 & 1 & 2 & 3 & 4 \\
\hline Palmitic acid & $\mathrm{C}_{16} \mathrm{H}_{32} \mathrm{O}_{2}$ & 38 & 34 & 34 & 34 & 44 \\
\hline Leinoleic acid & $\mathrm{C}_{18} \mathrm{H}_{32} \mathrm{O}_{2}$ & 40 & 44 & 51 & 41 & 33 \\
\hline Pentanoic acid & $\mathrm{C}_{16} \mathrm{H}_{30} \mathrm{O}_{2}$ & 7 & 0 & 0 & 0 & 0 \\
\hline Methyl linolelaidate & $\mathrm{C}_{19} \mathrm{H}_{34} \mathrm{O}_{2}$ & 3 & 2 & 3 & 3 & 3 \\
\hline Stearic acid & $\mathrm{C}_{18} \mathrm{H}_{36} \mathrm{O}_{2}$ & 8 & 7 & 7 & 0 & 8 \\
\hline Oleic acid & $\mathrm{C}_{18} \mathrm{H}_{34} \mathrm{O}_{2}$ & 0 & 8 & 0 & 7 & 9 \\
\hline Cis-7-Dodecenyl acetate & $\mathrm{C}_{14} \mathrm{H}_{26} \mathrm{O}_{2}$ & 0 & 0 & 0 & 9 & 0 \\
\hline Other $(<1$ area $\%)$ & & 4 & 5 & 5 & 6 & 3 \\
\hline
\end{tabular}


The main volatile components in the bio-oil for all of the experiments are $\mathrm{C}_{16}-\mathrm{C}_{18}$ aliphatic acids that have long carbon chains of hydrocarbons. These aliphatic acids make up more than $90 \%$ of the components indicated by the GC-MS on average. The aliphatic acids are believed to have formed from the lipids and possibly the proteins in the feedstock that had undergone decomposition and re-polymerization. Overall the bio-oil composition does not show large changes with the recirculation of the AP. This does not infer that the quantities of said components remain static throughout the experiments.

The FT-IR spectra for both the SCG and the bio-oil are presented in Fig. 4.

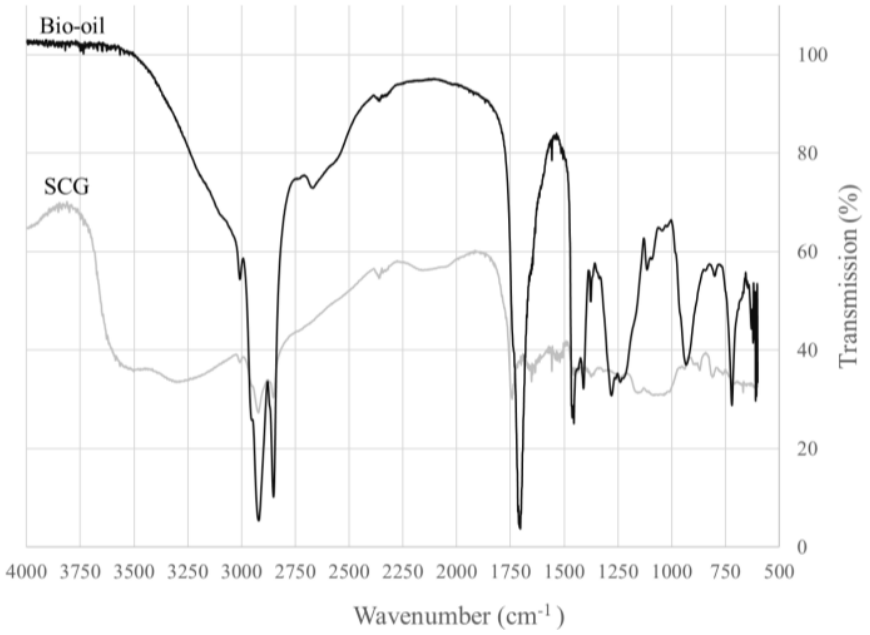

Fig. 4. FT-IR spectra of SCG and bio-oil

From Fig. 4 it is evident that similar functional groups are found in the SCG as in the bio-oil. The SCG had a broad absorbance in the $3400 \mathrm{~cm}^{-1}$ region which is indicative of high protein and carbohydrate content, this is however not the case for the bio-oil, thus suggesting that the HTL process had decomposed the proteins and carbohydrates.

Absorption peaks in the range of $2700 \mathrm{~cm}^{-1}$ to $3000 \mathrm{~cm}^{-1}$ due to $\mathrm{O}-\mathrm{H}$ bonds and stretching vibrations as well as in the range of $1650 \mathrm{~cm}^{-1}$ to $1750 \mathrm{~cm}^{-1}$ where $\mathrm{C}=\mathrm{O}$ stretching is identified are indicative of carboxylic acids along with ester groups. The absorbance peak was however larger for the bio-oil than for the SCG which suggests the formation of carboxylic groups during HTL.

Alkyl groups were also identified by the $1350 \mathrm{~cm}^{-1}$ to 1470 $\mathrm{cm}^{-1}$ absorption band caused by $\mathrm{C}-\mathrm{H}$ bending. Phenyl rings can be present as indicated by the adsorption peak from $670 \mathrm{~cm}^{-1}$ to $870 \mathrm{~cm}^{-1}$. The SCG shows an additional peak at $1050 \mathrm{~cm}^{-1}$ possibly due to $\mathrm{C}-\mathrm{O}$ that is connected to hydroxyl groups. The absence of this peak in the bio-oil absorption profile suggests that these hydroxyl groups were dehydrated in the HTL reactions.
The HHV that were obtained for the recirculation reaction reactions are reported in Table II.

TABLE II: THE HIGHER HEATING VALUES FOR BOTH THE BIO-OIL AND CHAR AS WELL AS FOR THE SCG FEEDSTOCK

\begin{tabular}{lcc}
\hline \hline & Bio-oil (MJ/kg) & Char (MJ/kg) \\
\hline Control & 34.07 & 29.46 \\
Recirculation 2 & 32.63 & 29.26 \\
Recirculation 4 & 32.61 & 29.94 \\
\hline & SCG & 20.03 \\
\hline \hline
\end{tabular}

The HHV of the first HTL reaction, the control experiment, showed a significant increase from the HHV of the feedstock for both the bio-oil and char. There was an increase of 14.04 $\mathrm{MJ} / \mathrm{kg}$ for the bio-oil and $9.43 \mathrm{MJ} / \mathrm{kg}$ for the char to reach 34.07 $\mathrm{MJ} / \mathrm{kg}$ and $29.46 \mathrm{MJ} / \mathrm{kg}$, respectively. This shows that HTL is effective in producing high energy content biofuels from biomass. However, there was a slight decrease noted in the biooil HHV following the AP recirculation reactions of 1.46 $\mathrm{MJ} / \mathrm{kg}$. This was thought to be caused by more oxygen containing species migrating to the bio-oil phase from the AP due to the saturation effects, which in turn causes the HHV to decrease slightly.

\section{3) Characterization of aqueous phase}

The results from the TOC, COD, -and TN testing kits are presented in Table III.

TABLE III: COD, TOC, AND TN TEST RESULTS FOR THE CONTROL, SECOND RECIRCULATION, -AND THIRD RECIRCULATION REACTIONS

\begin{tabular}{lccc}
\multicolumn{4}{c}{ RECIRCULATION, -AND THIRD RECIRCULATION REACTIONS } \\
\hline \hline $\begin{array}{c}\text { COD } \\
\left(\mathrm{mg}^{2} \mathrm{~L} \mathrm{O}_{2}\right)\end{array}$ & $\begin{array}{c}\text { TOC } \\
(\mathrm{mg} / \mathrm{L} \mathrm{C})\end{array}$ & $\begin{array}{c}\text { TN } \\
(\mathrm{mg} / \mathrm{L} \mathrm{N})\end{array}$ \\
\hline Control & 53405 & 55500 & 1750 \\
Recirculation 2 & 99341 & 50500 & 2120 \\
Recirculation 4 & 115709 & 39500 & 7220 \\
\hline \hline
\end{tabular}

The COD gives an indication of the organic species present in the AP. Initially the COD was $53405 \mathrm{mg} / \mathrm{L} \mathrm{O}_{2}$. The COD had increased with each recirculation reaction and nearly doubled by the $2^{\text {nd }}$ recirculation reaction with a value of 99341 $\mathrm{mg} / \mathrm{L} \mathrm{O}_{2}$. The final reaction had a COD value of $11709 \mathrm{mg} / \mathrm{L}$ $\mathrm{O}_{2}$, which showed that there was an increasing trend for the COD with an overall increase of $62304 \mathrm{mg} / \mathrm{L} \mathrm{O}_{2}$ or a $116 \%$.

Therefore, it is evident that concentration of organics in the $\mathrm{AP}$ is achieved when recycled the AP for subsequent reactions.

The overall increasing trend was also observed, even more so, for the TN of the AP. The initial TN value had been 1750 $\mathrm{mg} / \mathrm{L} \mathrm{N}$. This value had increased to $2120 \mathrm{mg} / \mathrm{L} \mathrm{N}$ by the $2^{\text {nd }}$ recirculation reaction. For the final recirculation reaction, the $\mathrm{TN}$ value was $7220 \mathrm{mg} / \mathrm{L} \mathrm{N}$. Therefore, an increase of 5470 $\mathrm{mg} / \mathrm{L} \mathrm{N}$ was observed which is a $312 \%$ overall increase.

The large increase in $\mathrm{TN}$ is due to degradation of the proteins in the SCG during HTL, releasing nitrogen containing components that migrate to the AP. The recirculation of the AP 
then causes concentration due to addition of nitrogen species from the previous reaction to the new species that was freed from the feedstock.

The opposite effect had however been observed for the TOC of the AP, with the TOC decreasing noticeably with each subsequent recirculation reaction. The TOC for the control was measured as $55500 \mathrm{mg} / \mathrm{L} \mathrm{C}$. A drop in TOC to $50500 \mathrm{mg} / \mathrm{L} \mathrm{C}$ had been noted by the $2^{\text {nd }}$ recirculation reaction. By the final recirculation reaction, the overall decrease was $16000 \mathrm{mg} / \mathrm{L} \mathrm{C}$ leading to a TOC value of $39500 \mathrm{mg} / \mathrm{L} \mathrm{C}$ for the $4^{\text {th }}$ recirculation reaction.

There had thus been a $29 \%$ decrease in the TOC over the course of the four recirculation reactions. When this decrease in carbon in the AP is coincided with the increase in the bio-oil mass yield, it gives validation to the notion mentioned previously that the material that was required for the mass yield increase in the bio-oil yield was gained from the AP.

Furthermore, a correlation between the increasing concentration of TN and organics (as indicated by COD) with the decreasing TOC and increasing bio-oil mass yield, would indicate that the saturation effects of organics in the AP causes migration of carbon species to the AP.

\section{CONCLUSION}

Recirculation of the aqueous phase is a plausible method that can be employed to increase the bio-oil yield during the HTL of SCG by more than $10 \%$ mass yield. It also has other benefits such as concentrating organics in the AP which can then be recovered as a value added by-product of the HTL process. The higher nitrogen and organics content also improve the prospect of using the AP from HTL for anaerobic digestion, however, further studies are required.

A reduction in the water requirement for HTL reactions is also possible when AP recirculation is used. The effects of further recirculation require more investigation along with determining the effects that other parameters such as temperature might have on the recirculation reactions.

\section{ACKNOWLEDGMENT}

The authors would like to acknowledge the National Research Foundation of South Africa for their financial support of this project. Any opinion, finding and conclusion or recommendation expressed in this material is that of the authors and the NRF does not accept any liability in this regard.

\section{REFERENCES}

[1] Kumar, M., A. Olajire Oyedun, and A. Kumar, "A review on the current status of various hydrothermal technologies on biomass feedstock." Renewable and Sustainable Energy Reviews, 2018. 81: p. 1742-1770.
[2] Nigam, P.S. and A. Singh, Production of liquid biofuels from renewable resources. Progress in Energy and Combustion Science, 2011. 37(1): p. $52-68$.

[3] Gollakota, A.R.K., N. Kishore, and S. Gu, A review on hydrothermal liquefaction of biomass. Renewable and Sustainable Energy Reviews, 2018. 81: p. 1378-1392.

[4] Elliott, D.C., et al., Hydrothermal liquefaction of biomass: Developments from batch to continuous process. Bioresource Technology, 2015. 178: p. 147-156.

[5] Ramos-Tercero, E.A., A. Bertucco, and D.W.F. Brilman, Process Water Recycle in Hydrothermal Liquefaction of Microalgae To Enhance Bio-oil Yield. Energy \& Fuels, 2015. 29(4): p. 2422-2430.

[6] Vardon, D.R., et al., Chemical properties of biocrude oil from the hydrothermal liquefaction of Spirulina algae, swine manure, and digested anaerobic sludge. Bioresource Technology, 2011. 102(17): p. 8295-8303.

[7] Yang, L., et al., Hydrothermal liquefaction of spent coffee grounds in water medium for bio-oil production. Biomass and Bioenergy, 2016. 86: p. 191-198.

[8] Murthy, P.S. and M. Madhava Naidu, Sustainable management of coffee industry by-products and value addition-A review. Resources, Conservation and Recycling, 2012. 66: p. 45-58.

[9] Klemmer, M., et al., Effect of Aqueous Phase Recycling in Continuous Hydrothermal Liquefaction. Industrial \& Engineering Chemistry Research, 2016. 55(48): p. 12317-12325.

[10] $\mathrm{Hu}, \mathrm{Y} .$, et al., Investigation of aqueous phase recycling for improving biocrude oil yield in hydrothermal liquefaction of algae. Bioresource Technology, 2017. 239: p. 151-159.

[11] Biller, P., et al., Effect of hydrothermal liquefaction aqueous phase recycling on bio-crude yields and composition. Bioresource Technology, 2016. 220: p. 190-199.

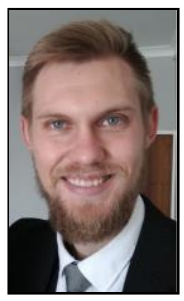

J.J Grobler was born on 17 November 1994. He matriculated from Afrikaans Hoërskool Kroonstad in 2013 and commenced his studies towards a bachelor's degree in chemical engineering at the North-West University (NWU) Potchefstroom campus in 2014. He has an interest in biofuels research field, more specifically the production of biofuels from biomass through the HTL process.

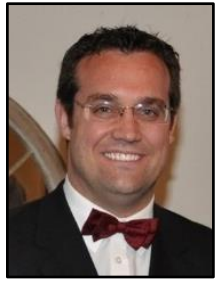

C.J. Schabort started his career as a process engineer at SASOL and joined the North-West University (NWU) in 2009 as a lecturer. He also became a member of the Biofuels Research group within the Faculty of Engineering. He holds both a bachelor's and a master's degree in chemical engineering, both obtained from the NWU. He is currently pursuing a $\mathrm{PhD}$ in chemical engineering in the field of renewable diesel produced from bio-oil derived from the HTL process using spent coffee grounds as feedstock. 